\title{
Does self-paced exercise depend on executive processing? A narrative review of the current evidence
}

Darías Holgado ${ }^{1} \&$ Daniel Sanabria ${ }^{1,2}$

${ }^{1}$ Mind Brain \& Behavior Research Center,

${ }^{2}$ Departamento de Psicología Experimental, Universidad de Granada, España.

\section{Corresponding Author}

Mind Brain \& Behavior Research Center

Universidad de Granada

Campus Universitario de Cartuja s/n

18011 Granada (Spain)

Telf. : +34 958247875

dariashn@ugr.es

Orcid: 0000-0003-3211-8006

Twitter:@DariasHolgado/@SanabriaLucenaD

This is a post-print version of the manuscript accepted for publication in the International Review of Sport and Exercise Psychology.

For citation: Holgado, D., \& Sanabria, D. (2020). Does self-paced exercise depend on executive processing? A narrative review of the current evidence. International Review of Sport and Exercise Psychology. https://doi.org/10.1080/1750984X.2020.1774915 


\begin{abstract}
Self-paced exercise is any physical activity in which the effort has to be distributed over time in order to achieve the objective of the event. Hence, self-paced aerobic exercise is a goal-directed behaviour towards an objective that involves several cognitive processes. The aim of the present review is to ask the extent to which self-paced exercise might rely on executive functions and the empirical evidence of top-down processing on self-paced exercise. We discuss the evidence from different experimental manipulations showing a potential link between self-paced exercise and executive processing. We finally highlight some gaps in the literature and possible factors that might mediate the role of executive processing and self-paced exercise. Self-paced exercise is likely to be a highly complex process, in which a multitude of factors non-related to executive functions can also contribute to the ultimate decision to upregulate or downregulate exercise intensity.
\end{abstract}

\title{
Keyword
}

Endurance; cognition; self-regulation; executive functions; exercise regulation; physical activity 


\section{Introduction}

Self-paced exercise, like running a marathon, refers to any physical activity in which the effort has to be distributed over time, in order to achieve the objective of the exercise. In a marathon, for instance, this would correspond to completing the set distance as fast as possible. Other cases exist in which athletes are expected to complete the greatest possible distance in a given time as in the cycling "Hour record". In all cases, it is of the essence to complete the set goal without reaching premature exhaustion (Edwards \& Polman, 2013). During such self-paced exercises, athletes have to continually process information from a myriad of internal (e.g., heart rate) and external (e.g., kilometer markers in a marathon road) inputs in order to achieve an optimal level of performance (Renfree et al., 2014). Selfpacing requires an individual to control and monitor the afferent feedback from the muscular and cardiopulmonary systems to various brain structures, which may affect directly or indirectly effort regulation (Roelands et al., 2013). Once this information is processed, athletes have to make continuous decisions to adapt the pace according to the demands of the event and remaining distance to cover or duration (St Clair Gibson et al., 2006). Moreover, athletes choose their pacing strategy based on the objective of the event as well as their previous experience. Greater experience should facilitate the choice of the adequate strategy (Brick et al., 2015). Therefore, self-paced exercise heavily rests on goaldirected behavior, given the requirement to adequately distribute effort over time to avoid premature fatigue. It may be argued then that executive processing would play a pivotal role in such goal-directed behavior.

Executive functions refer to a series of interrelated top-down processes which are needed for behavioral control, from selecting to monitoring behaviors in the service of goals achievement (Diamond, 2013). There are several frameworks related to the main components of executive functions (Friedman \& Miyake, 2017), but, for this review, we have adopted the framework proposed by Diamond (Diamond, 2013; Diamond \& Ling, 2019). According to this model, executive functions are composed of three core components: working memory, inhibitory control and cognitive flexibility (Diamond, 2013). Working memory involves the storage of information for a short period of time after it has been experienced. It is also at play when translating instructions into action plans or updating one's plan as one calculates or considers other alternatives. Inhibitory control is crucial to stop automatic behaviours, as when a tennis player has to avoid making a particular movement automatized after years of practice while trying to ameliorate his/her service, or when a pro cyclist who is used to reacting all opponent attacks in the final climbs has to refrain from leaving the peloton to comply with the team instructions. Inhibitory control is also central to selecting among many different possible choices the best memory representations, as when choosing the correct "breakaway" in a cycling peloton. Indeed, inhibitory control can be exercised at different levels, from self-control and discipline (inhibition at the level of 
behavior), to concentration and attention (suppression of unattended perceptual information) to cognitive inhibition (inhibition of thoughts or memories) (Diamond \& Ling, 2019). Finally, cognitive flexibility corresponds to the ability to switch between goals or modes of thinking, as when switching between tasks or considering multiple alternatives in a complex situation (e.g., a cyclist decides to wait for the team leader -with the goal of minimizing his/her loss of time - when in the front race with the goal of winning the stage).

This review asks the extent to which self-paced exercise engage and rely on executive functions. First, we briefly describe the current models put forward to explain the role of executive functions in selfpaced exercise. Second, we summarize the role of executive functions on self-paced exercise. We then discuss the empirical evidence from experimental manipulations with an eye toward possible causal links. Some studies have manipulated, before or during exercise, aspects of executive functions such as attentional focus, mental/cognitive fatigue and cognitive load to measure the impact on self-pacing. Other studies have asked whether self-paced exercise performance would be improved if executive functions were enhanced, whether through pharmacological drugs, brain stimulation, or cognitive training. Taking stock of the available literature, we argue for the role of executive functions in selfpaced exercises.

\section{Current models on the role of executive functions on self-paced exercise}

The current models on self-paced exercise have focused mainly on the neural basis of this goal-directed behaviour, with a particular interest in the prefrontal cortex (although there is little empirical evidence on this matter). The prefrontal cortex might indeed play a key role on self-paced exercise (Billaut et al., 2010), given its interconnection with other brain areas such as the anterior cingulate cortex and orbitofrontal cortex (Aron et al., 2007), premotor cortex and supplementary motor area, involved in the processing of sensorimotor information (Lutz, 2018). Robertson and Marino (2016) have proposed that the prefrontal cortex may act as a control structure which integrate information encountered during exercise, both centrally and peripherally, exerting a top down control (Robertson \& Marino, 2015). The prefrontal cortex would be responsible for integrating afferent signals provided by the anterior cingulate cortex and the orbitofrontal cortex, which have been related to motivational and emotional processing (Pollatos et al., 2007). Once these signals are integrated, the prefrontal cortex would respond consequently by increasing, decreasing or maintaining exercise pace, or ultimately stopping the exercise (Robertson \& Marino, 2015). Therefore, the costs and benefits analysis central to self-paced exercise would be mediated by the prefrontal cortex in concert with the anterior cingulate cortex and the orbitofrontal cortex (Cohen et al., 2005). If the cost overcomes the benefits (e.g., higher discomfort or risk of injury at the expense of better performance), inhibitory control over typical stopping mechanisms will be lifted so that the exercise pace can be down-regulated (Hilty et al., 2011). Likewise, McMorris 
and colleagues proposed a similar interpretation to that of Robertson and Marino's model (McMorris et al., 2018). They proposed that regulation of endurance exercise is based on interoception and motivation, but, in this case, is the ventrolateral prefrontal cortex, which integrates the information from the supplementary motor area and the premotor motor cortex, which ultimately sets whether to continue, slow-down or stop the exercise. These authors also highlight the importance of the anterior insula cortex that receives feedback from lamina I lateral spinothalamic and nucleus tractus solitarii medullo-thalamic pathways during exercise (McMorris et al., 2018), which reacts to changes of exercise intensity and perception of effort (Williamson et al., 1997). This feedback would be compared with the information stored in the memory in order to generate a new current status of awareness.

Although these two models are conceptually appealing, they are supported by only a few studies, all of which used externally-paced exercise instead of self-paced exercise. For example, Robertson and Marino's model (Robertson \& Marino, 2015) is based on the report that EEG activity assumed to arise from the dorsolateral and ventrolateral prefrontal cortex (note the poor spatial resolution of EEG) begins to decrease when exercise intensity overcomes the ventilatory threshold. It was inferred that these brain areas may exert a potential role on motor inhibition process. The authors argued that reduced brain activity in top-down control areas may favour the processing of unwanted stimuli which in turn, would lead to reduce the pacing or even stopping the exercise. Following the same logic, Enders and collaborators (Enders et al., 2015) found an increased prefrontal activity which matched with onset of force production and the transition from flexion to extension in the pedalling cycle. The authors suggested that the supplementary motor area received inputs from the prefrontal cortex, with its increased activation resulting in enhanced executive control, motor planning and execution (Enders et al., 2015).

Executive functions are also relevant to the psychobiological model of endurance performance (McCormick et al., 2015; Pageaux, 2014). This model emphasis five different cognitive factors related to self-paced exercise: 1) perception of effort; 2) potential motivation; 3) knowledge of the distance/time to cover; 4) knowledge of the remaining distance/time; and 5) previous experience of perception of effort during exercise. The model suggests that to overcome fatigue, the prefrontal cortex should exert inhibitory influences on the cingulate and insula cortices, both of which seem to be activated in proportion to the degree of subjective physical and mental fatigue (Cohen et al., 2005; McCormick et al., 2015). Therefore, according to the psychobiological model, the key variable on self-paced performance is the perception of effort (Pageaux, 2014).

There are several psychological interventions supporting the psychobiological model of endurance exercise (McCormick et al., 2015), but we are only aware of limited evidence supporting the neural basis of this model, with all studies manipulating mental fatigue prior to exercise (see section 3.3 for more discussion on this issue). For example, Brownsberger et al. (2013) and Pires et al. (2018) found 
that cyclists with an induced state of mental fatigue presented an increased EEG brain activity in the prefrontal cortex. In Brownsberger' et al. study, twelve participants completed two consecutive selfpaced cycling exercises at RPE of 11 or 15 , after completing a 90 min mental fatigue task or watching a documentary. The authors found that participants produced less power output during the self-paced exercise in the mental fatigue condition compared to the control condition, and it was related to a higher beta activation in the electrode position F3 for the mental fatigue condition. The authors suggested that the higher beta activation in F3 might be related to prefrontal activity. Meanwhile, Pires et al. (2018) showed that a group of eight trained cyclists with an induced state of mental fatigue presented a higher theta activation during a $20 \mathrm{~km}$ cycling time trial than in the control condition. Moreover, cyclists in the mental fatigue condition completed the $20 \mathrm{~km}$ time-trial slower than in the control condition and the authors suggested that increase theta power might reflect their lower ability to preserve adequate inhibitory control and attentional allocation during exercise, which subsequently led to impaired performance (Pires et al., 2018). These results, however, should be interpreted with caution, because of he small sample sizes of these studies (less than 15 participants), the level of participants (recreational athletes), and the fact that Pires et al. (2018) only placed one electrode to record EEG activity.

The Central Governor Model proposes that self-paced exercise is regulated by the central nervous system to ensure that exercise terminates before there is a biological failure (Noakes, 2011). In this model, the endpoint of the exercise is a known variable by which the central governor continually manipulates self-pacing regulation. In a recent review, Venhorst et al. (2018) developed this theoretical proposal arguing that self-paced exercise is based on a construct of three-dimensional categories. First, perceived mental and physical strain are the main components of exercise which reflect the sensorydiscriminatory process necessary to match the planned objective with the physiological state. Second, core affect has a mediatory role in the regulation of effort since its two dimensions, hedonic and arousal, reflect behaviour of approaching or avoidance. Third, cognitive flexibility is of the essence to weigh between further pursuit of the goal and goal disengagement, according to the boundaries set by homeostasis.

Research into the neural basis of the mechanisms proposed by the Central Governor Model is, however, in its infancy. A recent attempt comes from the study by Fontes et al. (2020), who showed selective activity in brain areas associated with autonomic regulation (e.g., the left insular cortex) during an incremental cycling exercise. For the authors, activation of the insular cortex would support the notion of the Central Governor Model, because of its key role in monitoring the afferent feedback from the cardiovascular system, contributing to the control of exercise to avoid biological failure. Moreover, these authors also found a deactivation of the prefrontal cortex, that was interpreted as evidence of the unconscious control to sustain the body homeostasis during exercise (since the activation of the prefrontal cortex has been typically related to top-down conscious processing León-Domínguez \& León-Carrión, 2019). 
Finally, the Reticular-Activating Hypofrontality model of Dietrich and Audiffren (2011) is also worth mentioning in this context. This model proposes that humans have a limited set of metabolic and cognitive resources and when these resources are shared amongst several tasks, interference occurs between them. Given that neural processing occurs in a competitive basis, the increasing activity in some brain areas would be followed by a shift in the activity in other brains areas to allow the adequate allocation of resources in those areas requesting more activity. They proposed that the shifting and allocation of resources would vary mainly due to the type, the duration and intensity of exercise. This model also highlights automaticity as a key factor for exercise regulation, since the more a task is automated, the more resources would be available to allocate in different task-relevant aspects (Dietrich \& Audiffren, 2011). This model is relevant to understand the impact of executing two tasks at the same time (i.e., cognitive load) and that of the expertise level of athletes, i.e., experts would have automatized more aspects of the exercise task leaving more cognitive and metabolic resources available for other secondary tasks.

In summary, notwithstanding the discrepancies on the main focus between these models of self-paced (endurance) performance, all of them consider executive functions and the prefrontal cortex, its associated neural mediator, as determinants for self-paced aerobic exercise. However, as we summarize here, few empirical studies have tested the neural mechanisms of self-paced aerobic exercise. In addition, we are still far from understanding the connection between brain areas recruitment and exercise as it unfolds, let alone the possible mediating role of executive functions.

\subsection{Role of executive functions on perceived exertion during self-paced exercise}

The models described above agree in that self-paced exercise involves several cognitive processes, such as perception and memory, as well as executive functions, such as inhibition and working memory (Hyland-Monks et al., 2018; Jacobson \& Matthaeus, 2014b; Smits et al., 2014). Stimulation from internal organs (e.g., muscle, lungs, heart) and from environmental factors (e.g., competitors, public, road surface) need to be processed and integrated requiring athletes to select relevant sources of information and suppress potential distractions (Vickers \& Williams, 2017). For example, based on their breathing sensation, athletes can rate how they perceive a given physical effort (Johnson et al., 2009). However, accurate perception of effort builds on a mental template that have been previously defined through experience to avoid premature fatigue and maximize performance (Foster et al., 2009). Indeed, athletes might perceive a given effort lighter or more strenuous depending on, not only the exercise intensity and the estimated duration until ending the exercise, but also their prior knowledge about these types of exercises (de Koning et al., 2011). A common measure of effort in exercise performance is the rate of perceived effort (RPE). Briefly, RPE in sports might be described as the cognitive feeling associated to physical effort (Pageaux, 2016) or the process of investing a given amount of physical or mental resources out of the perceived maximum to perform a specific task 
(Halperin \& Emanuel, 2019). Importantly, RPE might be linked to several executive processes, such as working memory, inhibition, self-control and attention (Taylor et al., 2018).

As we mentioned before, during self-paced exercise, athletes have to continuously update their initial plan according to the current demands of the exercise. If the current performance is under or over the desired goal, athletes will have to calculate or consider new alternatives, and switch motor plans accordingly (Baron et al., 2011; Foster et al., 2009). In other words, when athletes assess their current RPE, they rely on key executive functions of working memory, inhibition and cognitive flexibility.

The RPE also relies on inhibitory process related to the self-paced exercise (Verhoeven et al., 2011). During self-paced exercise, the adequate management of sensation helps to achieve an optimal level of performance, as the regulation of effort is associated with the ability to tolerate and inhibit discomfort raised during exercise. Maintaining an exercise despite feeling fatigue or pain in some part of the body (Verhoeven et al., 2011) and/or hard environmental conditions (Davies et al., 2016) implies that the urge of stopping or reducing the exercise intensity must be inhibited (Audiffren \& André, 2015; Verhoeven et al., 2011). Therefore, inhibitory process, such as focused attention or self-control (Brick et al., 2015; Diamond, 2013), help to regulate self-paced exercise.

We now turn to, arguably, the most widespread practice in the literature which is to look for manipulations that have an effect on executive functions, with the end goal of measuring how exercise performance may improve or worsen as a result of such manipulations. In the following section, we summarize the evidence from experimental studies that aimed at investigating the influence of executive functions over self-paced aerobic exercise performance.

\section{Experimental manipulations affecting executive functions and self-paced performance}

\subsection{Attentional focus}

During self-paced exercise athletes have to allocate their attentional resources only toward relevant stimuli from the myriad of inputs (internal and external) that reach the central nervous system. For instance, when athletes adopt different focus of attention, they will mainly call upon inhibitory process such as inhibition of thoughts, selective attention or self-regulation. Accordingly, attentional focus during self-paced exercise has been a topic of interest for sport scientists (Brick et al., 2014). It has been generally accepted that athletes can choose among two different attentional strategies - associative or dissociative - along two separate dimensions of information - internal or external (Stevinson \& Biddle, 1998). On the one hand, within the associative strategy, athletes can focus their attention towards relevant aspects of the exercise, either internal (i.e., focusing on internal body aspect of the task such as 
breathing, heart rate, etc.) or external (i.e., focusing on monitoring the competition such as pace, power output, remaining distance, etc.). On the other hand, in the dissociative strategy, athletes divert their attention to irrelevant aspects of the exercise, such as irrelevant daydreams or math puzzles (internal dissociation) or in the scenery or other competitors (external dissociation). Interestingly, Brick et al., proposed a clearer framework to guide future research on this topic (Brick et al., 2014). They propose that attentional focus during endurance activities should be considered under four dimensions: active self-regulation, outward monitoring, internal sensory monitoring and distraction (either active or involuntary). In this section, however, we will use the traditional framework (associative/dissociative), since it has been the terminology used by the studies included here.

The logic of the attentional focus theory is that focusing on the task or diverting the attention away from the task might affect (mainly) subjective indexes of exercise performance, and consequently affect physical performance (Brick et al., 2014). For example, Connolly and Janelle (2003) in their first experiment studied the effect of an associative versus dissociative strategy on self-paced rowing performance. In the associative strategy, participants $(n=8)$ completed more distance than in dissociative strategy, although there was no difference in RPE levels between conditions. In their second experiment, they tested the two dimensions of associative and dissociative strategies with respect to internal or external information. In five separate visits, participants completed a $2000 \mathrm{~m}$ self-paced rowing exercise using internal/external associative or dissociative strategies and a baseline condition (Connolly \& Janelle, 2003). An associative strategy (both internal and external), induced higher RPE levels and better performance compared to the baseline condition during a self-paced exercise. However, there were not differences between the internal dissociative condition and the external dissociative condition when compared to the baseline condition or the two associative conditions. The authors concluded that the higher RPE might be better explained by the better physical performance in the associative strategy, rather than the associative strategy itself calling for further controls compared to dissociative strategies. In terms of Brick et al.'s proposal (Brick et al., 2014), the active self-regulation of effort may enhance endurance performance by optimizing the pace.

Williams et al. (2015) suggested that focusing attention on external aspects of a self-paced exercise improves physical performance. Williams et al. used a cyclists' avatar, which simulated a competitor with higher power output than the participant at baseline, to reduce the internal associative focus during a self-paced $16.1 \mathrm{~km}$ time-trial compared to a neutral or no avatar condition. On average, participants ( $\mathrm{n}$ $=15$ ) completed the cycling time-trial $1.4 \%$ faster and increased the average power output $2.8 \%$ compared to the baseline. The higher performance was achieved by an altered pacing strategy (i.e., alter self-regulation thoughts) throughout the time-trial, as the external (associative) focus might have allowed athletes to reduce negative sensation of fatigue and pain (Williams et al., 2015). According to the authors' conclusion, the external focus helped to inhibit the rise in RPE during exercise since participants paid less attention to the RPE. In a separate study, Williams et al. (2016) found that 
enforcing a slower initial pace during the first $4 \mathrm{~km}$ of a $16-\mathrm{km}$ cycling time-trial reduced the internal association focus compared to a fast or a neutral start. Although cyclists started slower than normal pace, the positive psychological responses during the initial phase of the time-trial reduced the RPE, but it did not affect the overall time-trial performance compared to fast and baseline start.

Robinson et al. (2018) asked nine active adults to match the $80 \%$ of a 3-min all-out test, during a 3-min cycling self-paced exercise by using an internal associative strategy or external dissociative strategy. They found that using an associative strategy, participants completed the test at their $75.9 \%$ of the average power output obtained in 3-min all-out test performance, whereas with the dissociative strategy participants were only able to achieve $70.9 \%$ of their performance. They argued that in novice participants, distracting the attention from performance (i.e., active distraction) can slow down the pacing, and therefore an internal (associative) focus strategy might help to maintain a more consistent performance throughout a self-paced event (Robinson et al., 2018).

In conclusion, although the attentional focus during self-paced exercise might be of paramount importance for exercise regulation and it is linked to executive functions, there are only a few self-paced exercise studies (see Brick et al., 2014) in which the attentional focus has been manipulated externally and the results are somewhat mixed. An associative strategy might increase RPE, but it might be mediated by an increased performance (Connolly \& Janelle, 2003; Robinson et al., 2018). Yet, a external association strategy (i.e., outward monitoring) might improve exercise performance (Williams et al., 2015) without increasing RPE (Williams et al., 2016), at least in more proficient athletes.

The role of inhibitory control in self-paced performance is highlighted by its key role in sustaining goaldirected behavior and attentional focus (Brick et al., 2014). It is indeed important to acknowledge that attentional focus is a dynamic process in which athletes might focus on different aspects of exercise according to exercise intensity. For example, during low intensity phases of exercise athletes might focus on task-unrelated cues (i.e., dissociation), but as the exercise intensity increases athletes would allocate their resources more on task-related cues (i.e., association) which might help them to optimize performance (Bigliassi, 2015; Hutchinson \& Tenenbaum, 2007). Nonetheless, on the majority of the experiments reviewed here participants are requested to perform their best, thus the exercise intensity would tend to be high from the beginning and hence one would not expect a change in the attentional focus. Moreover, previous experience in self-paced activities may also alter the nature of the optimal strategy (see section 5 below). Finally, the exercise protocol might have some implication for regulation, since distance-based exercise protocols seem less cognitively demanding than time-based tasks (Chinnasamy et al., 2013). 


\subsection{Cognitive load during self-paced exercise}

There is a wealth of literature on the behavioural dynamics related to executive functioning during acute exercise (Lambourne \& Tomporowski, 2010; Ludyga et al., 2016). However, much less studies have evaluated the extent to which self-paced exercise performance depends of cognitive load. Under the umbrella of cognitive load, we refer to those interventions aiming to induce different levels of cognitive (executive) load during a self-paced aerobic exercise. For instance, Epling et al. (2016) found that performing a word recall task involving working memory while participants completed a self-paced outdoor running exercise, increased the mental workload (measured with the NASA-TLX scale) compared to running without performing any cognitive task. However, they did not find that the cognitive task performed during a 5-min self-paced run affected the distance covered by the 12 athletes. Likewise, Blakely et al. (2016) examined the impact of cognitive load (tone counting with two levels of difficulty) on a group running on an even surface and on a group running on an uneven (trail) surface. In Blakely' study, participants reported higher mental workload and feelings of being mentally exhausted with the more demanding cognitive task. Nonetheless, they only found a linear trend in both groups for a worsening physical performance as cognitive task difficulty increased.

In contrast to the above-mentioned studies, Holgado et al. (Holgado, Zabala, et al., 2019) found that performing simultaneously a n-back task, which involves working memory and inhibition, did not seem to affect exercise performance during a 20-min self-paced cycling exercise in 28 trained cyclists. The results of the study did not show enough evidence to support the idea that completing a challenging cognitive task (2-back) compared to the less challenging task (1-back) affected the average power output achieved. In addition, the results of the study showed that, despite the higher cognitive demands of the 2-back condition, RPE was not affected by the cognitive load. Similarly to this finding, Daniels and Newel (2003) did not find an increase in the RPE while participants completed a hard math task during a self-paced running exercise.

Evidence of the impact of cognitive load on self-paced exercise also comes from the literature on gating performance. Indeed, walking, when performed with a specific goal (e.g., to cover a given distance in a certain amount of time) can be considered a self-paced exercise. For example, Malcolm et al. (2018) found that increasing the cognitive load (using a go/no-go response inhibition task) while participants walked on a treadmill modified the gait pattern during the more challenging task compared to the control condition. In contrast, Schaefer et al. (2015) did not find that the cognitive load (2-back vs. 3-back) affected walking patterns at a self-selected speed in healthy young adults. Although walking (gait) exercise is beyond the scope of this review, these examples clearly reflect that the effect of cognitive load in healthy adults in a less complex self-paced exercise, such as walking, is also not robust. 
In conclusion, the current evidence does not allow one to reach any firm conclusion on the effects of cognitive load on self-paced exercise performance, as the published studies remain scarce and greatly vary in the methodology. This being said, the current evidence does not support the idea that performing simultaneously a challenging cognitive task during self-paced exercise impairs exercise performance. As mentioned above and discussed below (see section 5), and considering the Reticular Hypofrontality model (Dietrich \& Audiffren, 2011), it is plausible that other factors, such as level of expertise, may modulate or even mask the effect of cognitive load on self-paced exercise.

\subsection{Mental fatigue before self-paced exercise}

It is commonly believed that performing a long and challenging cognitive task involving executive functions (e.g., inhibitory control, cognitive control, etc.) before exercise might increase the RPE in a subsequent exercise due to an induced state of mental fatigue (Marcora et al., 2009). In this state of mental fatigue, athletes would select a lower self-selected exercise intensity, as they would find it harder to inhibit unpleasant stimuli related to successful exercise performance (Van Cutsem et al., 2017). It is hypothesized that the state of mental fatigue is caused by an accumulation of adenosine within the brain regions recruited by the demanding cognitive task (Martin et al., 2018). Adenosine might have two effects: first it would increase the RPE and second, it would reduce motivation towards the exercise. However, this hypothesis has not been tested in experimental studies yet and therefore, it remains speculative whether RPE increases as a consequence of an accumulation of adenosine within active regions of the brain (Martin et al., 2018). Note that RPE should not be interpreted in isolation, since no change in RPE in the presence of a decreased performance (e.g., slower time or decreased power output) might suggest an increased perceived exertion (Schiphof-Godart et al., 2018).

The literature on the effects of performing a challenging cognitive task before self-paced aerobic exercise remains somewhat inconsistent and scarce. For example, Pageaux et al. (2014) found that performing a 30 min inhibitory control cognitive task (Stroop task) induced a higher RPE and reduced the physical performance on a $4 \mathrm{~km}$ self-paced running exercise in 12 physically active participants compared to performing the same exercise without the initial inhibitory task. Similarly, but using a 30 min sustained attention cognitive task before exercise, Pires et al. (2018) showed that the cognitive task induced a higher RPE and participants needed more time to complete a $20 \mathrm{~km}$ time-trial in a group of 8 recreational active participants in comparison to a control condition (seated for $30 \mathrm{~min}$ ). However, contrary to Pageaux et al. (2014), Penna et al. (2018) did not find that the same cognitive inhibitory task affected the RPE in 16 highly trained swimmers, although it impaired their performance in a $1500 \mathrm{~m}$ self-paced swimming exercise. Likewise, Martin et al. (2016), using the same task and duration as in Pageaux's and Penna's studies, did not find any effect of prior mental fatigue on the RPE levels of professional cyclists $(n=11)$ and recreational cyclists $(n=9)$. However, the group of recreational cyclists impaired their physical performance in a 20 min cycling time-trial, whereas no changes were 
shown in the group of professional cyclists. Martin et al. concluded that professional riders might be more resilient to mental fatigue and have a superior inhibitory control (Martin et al., 2016). Contrary to the findings of Martin's et al. study, Clark et al. (2018) reported similar self-paced performance (6-min cycling time-trial) after completing a fatiguing Stroop task or a neutral task independently of whether participants were competitive cyclists $(n=10)$ or untrained $(n=10)$.

Other studies have induced mental fatigue through longer cognitive task. However, even longer cognitive tasks do not seem to induce consistent detrimental effects on RPE or physical performance. For example, Staiano et al. (2018) asked 13 young elite kayakers to perform a 60 min Stroop task before a 2000m self-paced kayaking time-trial. Participants were indeed impaired in the self-paced exercise (time to complete the $2000 \mathrm{~m}$ ) probably due to a higher RPE in the mental fatigue condition as compared to the control condition. In contrast, Filipas et al. (2018) did not find that the same task and duration affected RPE or physical performance in prepubertal kayakers' athletes before completing a $1500 \mathrm{~m}$ time-trial. Performing the AX-CPT task, which involves sustained attention, working memory, response inhibition, and error monitoring, for 90 min affected neither RPE nor physical performance on a sample of 8 recreational cyclists before a $4 \mathrm{~km}$ cycling time-trial (Silva-Cavalcante et al., 2018). In contrast, the same cognitive task impaired $3 \mathrm{~km}$ running performance on 20 recreational runners, even though participants did not rate their RPE higher (MacMahon et al., 2014).

In summary, the above evidence points out that performing a cognitive task which involve executive functions prior to self-paced exercise might at worse have a detrimental effect on RPE and self-paced exercise performance, and at best no effect. The mechanisms underlying the possible negative effect is certainly unclear (Martin et al., 2018), and the mixed results in the literature do not provide a strong evidence to support a systematic detrimental impact of mental fatigue on self-paced exercise (Van Cutsem et al., 2017). This idea has been supported by the results of recent meta-analyses. For instance, McMorris et al. (2018) concluded that the effect of mental fatigue on exercise might be likely due to random variations. Meanwhile, Holgado et al. (2019) showed a negligible effect of mental fatigue on exercise performance when correcting for publication bias. As noted in Holgado et al., the funnel plot asymmetry in Brown et al.'s meta-analysis (Brown et al., 2019) also points to publication or reporting biases. Together with this potential publication bias, the results from the empirical studies should be interpreted with caution for the following reasons: first, sample sizes are generally low (less than 20 participants) which may lead to overestimation of effect sizes; second, the experimental and control conditions usually varied in several components, such as the duration of the interventions (Martin et al., 2016) or performing a cognitive task versus doing nothing in the control condition (Martin et al., 2016; Penna et al., 2018; Pires et al., 2018; Silva-Cavalcante et al., 2018; Staiano et al., 2018). 


\section{Interventions to enhance self-paced performance by the effect on executive functioning.}

The proposal that executive functions have a role in the self-regulation of endurance performance has led some authors to hypothesize that enhanced executive functions would result in improved self-paced aerobic exercise. In this section, we will discuss those interventions which may have the potential to improve self-paced exercise performance by acting, directly or indirectly, on executive functions. These interventions include, but are not limited to, cognitive training, non-invasive brain stimulation or pharmacological substances (Enriquez-Geppert et al., 2013).

Whether cognitive training or brain stimulation, the logic of the existing studies is straightforward: any change in areas associated with executive functions should affect self-paced exercise, to the extent that self-paced exercise rely on executive functions. Thus, cognitive training in sport has been mostly targeting those executive functions, such as working memory or inhibition, that should transfer to enhanced sport performance in real-world situations (Walton et al., 2018). Yet, given that cognitive training typically results in narrow transfer effect or improvements on the trained task with only limited generalization to other tasks, the possibility that cognitive training improves a sport specific task, which would be a typical case of broad transfer, remains controversial (Furley \& Memmert, 2011). There is some evidence supporting the idea that high-performance athletes from different sports perform better in untrained executive functions tasks related to their sports (Krenn et al., 2018). Even if this is a topic of great interest, there is not enough evidence showing a benefit in the opposite direction, i.e., a positive effect of a cognitive training in self-paced exercise (Harris et al., 2018). The limited evidence to date comes mainly from studies supported by commercial companies rather than from peer-reviewed ones (Walton et al., 2018). Therefore, it seems too early to recommend cognitive training for athletes due to the time-cost balance. Finally, connected to cognitive training, there is preliminary evidence that suggests that the employment of active cognitive strategies during exercise might help to the regulation of effort, or at least to reduce the perception of effort (McCormick et al., 2015). Although most of the researches have employed externally-paced test, there is some rationale to think that self-regulation (Wolff et al., 2018), cognitive reappraisal (Giles et al., 2018) or self-talk strategies (Hatzigeorgiadis et al., 2011) might help athletes to better allocate their cognitive resources toward task-relevant aspects, and subsequently improve endurance performance.

Transcranial direct current stimulation (tDCS) is the main non-invasive brain stimulation technique used in Sports science in order to improve exercise performance. Although tDCS is branded as enhancing executive functions, few studies have used self-paced exercise to test the effects of tDCS on performance. Anodal tDCS applied over the left temporal cortex before exercise did not improve performance compared to the sham condition in a $16 \mathrm{~km}$ self-paced time-trial in male trained cyclists 
(Barwood et al., 2016). Stimulation of the left dorsolateral prefrontal cortex before a $20 \mathrm{~km}$ time-trial in healthy men (Simpson, 2017), and before a 20 min time-trial on male trained cyclists (Holgado, Zandonai, et al., 2019) did not improve performance either. tDCS over the motor cortex before an $800 \mathrm{~m}$ swimming test also failed to enhance performance in elite triathletes (Valenzuela et al., 2018). Moreover, stimulating the prefrontal cortex for $20 \mathrm{~min}$ did not elicit any change in oscillatory brain activity either at baseline or during exercise (Holgado, Zandonai, et al., 2019). Hence, the current evidence available does not support the claim that tDCS is able to improve self-paced performance. Moreover, despite the general belief that tDCS is an effective tool to improve exercise performance, the pooled effect size of the tDCS' studies on objective and subjective measures of exercise performance or muscle strength do not provide much evidence for its ergogenic effect. Indeed, the effect might be mainly driven by studies with low quality and by publication bias (Holgado, Vadillo, et al., 2018; Machado et al., 2018). As for the case of cognitive training, companies with commercial interests have been promoting tDCS without solid evidence of its effects on exercise performance (Reardon, 2016).

Finally, it is worth mentioning that there has been a trend for athletes from all levels to use pharmacological drugs (e.g., analgesics or opioids) or ergogenic aids (e.g., caffeine). Athletes might be using these drugs in order to inhibit process related to exercise induced pain or discomfort and reduce RPE (Holgado, Hopker, et al., 2018). Some of these pharmacological drugs are, for example, paracetamol or tramadol. Paracetamol might inhibit pain sensation by decreasing the activation of the anterior cingulate or prefrontal cortices, which are linked to executive functions and to pain and cognitive/ affective processing. For instance, Mauger et al. (2010) found that paracetamol ingestion increased the average power output and reduced the time required to complete a $16.1 \mathrm{~km}$ self-paced cycling exercise, although the RPE remained unchanged. Likewise, tramadol, might reduce the ability of the brain to respond to sensory inputs by inhibiting serotonin and norepinephrine reuptake. It is therefore possible that tramadol could improve exercise performance via its effect on central brain areas associated with perception of effort, but at the expense of reducing sustained attention (i.e, the ability to keep focused on a task over the time). Holgado et al. (Holgado, Zandonai, et al., 2018) conducted the first study, to the best of our knowledge, to test the hypothesis that tramadol improves self-paced performance. In their first experiment, they showed that tramadol allowed trained cyclists to achieve greater mean power during a self-paced exercise without modifying brain electrical activity or RPE. In contrast, in a second experiment aimed to replicate the first study and to test the hypothesis that tramadol might have an effect on sustained attention during exercise, tramadol did not improve physical performance or affect sustained attention at the behavioral level compared to the placebo condition (Holgado, Zandonai, et al., 2018). These authors found, though, that tramadol caused a lower brain activity (i.e., greater suppression with respect to the baseline) in the alpha frequency band linked to stimulus processing (relevant to the task) in the condition of tramadol compared to placebo which might suggest a detrimental impact of tramadol on stimulus processing. In contrast, another recent study found 
that tramadol did not affect physical, cognitive or motor function in trained cyclists (Bejder et al., 2019). In Bejder et al.'s study, participant completed a a fatigue protocol (1h at $60 \%$ of peak power) followed by a $15-\mathrm{km}$ time trail after ingesting tramadol or placebo. In sum, more research is warranted to establish the effect of tramadol on self-pacing exercise at the physical, cognitive and brain levels. For further discussion on the effect of pharmacological substance on exercise performance see the reviews by Lundberg and Howatson (Lundberg \& Howatson, 2018) and Holgado et al. (Holgado, Hopker, et al., 2018).

Similarly, caffeine is a stimulant that blocks adenosine receptors and increases endorphin release. Indeed, there is a wealth of studies supporting the benefit of caffeine for self-paced exercise (Grgic et al., 2019). Caffeine might improve exercise performance by improving neuromuscular function and vigilance and alertness. Moreover, it might reduce the RPE during exercise (Burke, 2008). Given its ergogenic effect, caffeine might contrarrest the aforementioned negative effect, if any, of mental fatigue on self-paced performance (Franco-Alvarenga et al., 2019; Van Cutsem et al., 2018). In the FrancoAlvarenga et al.'s study (Franco-Alvarenga et al., 2019), participants ingested caffeine or placebo immediately before a 40-min cognitive fatiguing task designed to generate a mental fatigue state and prior to complete a $20 \mathrm{~km}$ cycling time-trial. The results of the experiment showed that despite the increasing sensation of mental fatigue, twelve trained cyclists improved their self-paced performance (i.e, higher average power output and faster time in the time-trial) and reduced their RPE after caffeine ingestion in comparison to the placebo condition. However, the prefrontal cortex activation remained unaltered between conditions, so it is plausible that the reduced RPE and increasing affect and emotional arousal during the time-trial explained the positive benefit of caffeine (Franco-Alvarenga et al., 2019). For further discussion on the effect of caffeine on exercise performance, readers are referred to the thereviews by Burke (2008), Ganio et al. (2009), and Grgic et al. (2019)

\section{Level of expertise}

There is some rationale to think that the level of expertise in a given skill might be fundamental to explain the extent to which skills rely or not on the use of executive functions. It is plausible that through deliberate practice many of the exercise skills or movements might be performed, for example, with little or no reliance on executive functions (Smits et al., 2014). Given that the use of executive functions is effortful and that cognitive resources are limited, exercise expertise would be valuable in reaching an automatic mode in order to divert effortlessly resources where and when they are needed. According to some models, learning new skills go through different stages (Schaefer, 2014). In a first stage, movements are performed consciously by investing large amounts of cognitive resources. In the next stage, movements are executed in a blend of aware and automatized control strategies. Finally, some athletes reach an autonomous stage, in which cognitive resources are no longer allocated to the 
execution of movement, but resources are allocated to processing other task-relevant information. Neuroimaging studies corroborate this idea, as prefrontal cortex activity is seen to decrease from the initial phase of learning a new skill to once the skill becomes more automatized (Erickson et al., 2007; Floyer-Lea \& Matthews, 2005). These studies show that with increasing automaticity of movements, control demands are reduced and activity in participating control brain areas decline (Erickson et al., 2007; Floyer-Lea \& Matthews, 2005). Hence, with a high level of automaticity, processes are more efficient, rapid, smooth and require lower levels of control capacity (Debarnot et al., 2014).

Athletes with a higher level of expertise would therefore rely to a lesser extent on executive functions while exercising. For example, when athletes achieve a high level of automaticity, movements are better adjusted and require less energy expenditure and cognitive effort (Neubauer \& Fink, 2009; Schmidt \& Lee, 2014). Experts might also require less cortical activity to perform the same task compared to novices. For instance, Ludyga et al., (2015) found that cyclists with higher fitness level had less brain cortical activity in beta band frequency in comparison to a group of lower fitness level cyclists, during a 30 min submaximal cycling exercise below the ventilatory threshold. The authors speculated that the reduced beta power and the higher alpha/beta ratio were due to fact that high fit cyclists were more efficient and relaxed. We acknowledge that the exercise intensity in this study was fixed, and therefore the results might not extrapolate to a self-paced aerobic exercise. Note also that higher fitness might not directly be linked to a higher expertise in a physical exercise.

An example closer to self-paced aerobic exercise, as noted above, comes from the gait literature. There is evidence that different steady state walking speeds do not considerably affect prefrontal activation (Meester et al., 2014; Suzuki et al., 2004). As gait is a skill that has been automatized throughout life, prefrontal activity (with respect to rest) remains relatively stable even at different comfortable speeds. Similarly, experts' athletes through deliberate practice over the years may have developed the ability to execute their skill free of much frontal cortex participation for the movement they are executing, and these resources might be employed for task relevant information and goal-directed self-regulation. Although gait and many self-paced aerobic exercises might be considered similar tasks (i.e., cyclical and continuous activities), we cannot directly extrapolate these results to these more complex self-paced (higher intensity) exercises.

Interestingly enough, the study of Martin et al. (2016) described above, concluded that professional cyclists showed better inhibitory control and were more resistant to the negative effect of a high mental fatigue. In Martin et al.'s study, the group of professional cyclists did not display impaired performance in a 20 min time-trial after completing a 30 min Stroop task compared to a 10 min seated control condition. However, the group of recreational cyclists displayed impaired physical performance in the mental fatigue condition and made more errors in the Stroop task. Likewise, Cona et al. (2015) found that faster ultra-distance runner had better inhibitory control in a go/no go task than slower runner before 
an ultra-marathon running race. Furthermore, Jacobson and Matthaeus found that self-paced athletes outperformed both externally-paced athletes and non-athletes in a task involving inhibitory control (Jacobson \& Matthaeus, 2014a), which supports the conclusion of Ludyga et al.'s study (Ludyga et al., 2015) suggesting that high fit cyclists might have a better inhibitory control. In summary, it seems that a better baseline inhibitory control would allow athletes to allocate their cognitive resources toward task-relevant aspect of self-paced exercise, which ultimately would help them to improve performance and reduce the perception of effort. Future studies should also compare whether it is also true that high fit athletes have a higher inhibitory control during exercise.

Additional evidence for the influence of expertise level on the link between executive functions and self-paced exercise comes from attentional focus strategy studies. For example, experts (or those athletes with better performance), adopt different attentional strategies during self-paced exercise compared to novice athletes. For example, Silva and Appelbaum (1989), found that top finishers in a marathon race spent more time using an internal associative focus of attention compared with the slower finishers. These observations are consistent with those of Morgan and Pollock (1977), who determined that high-level performers runners also utilized internal associative strategy, whereas non-elite runners appealed more often to an external attentional focus strategy. This is further supported by Stevinson and Biddle (1998), as they found a correlation between the use of an internal dissociative attentional focus strategy in non-elite marathon runners and "hitting the wall" in a marathon race compared with those participants that they did not use primarily this strategy. They suggested that the internal dissociation (i.e., focusing in internal aspect not relevant to the task such as daydreaming) is a hazardous strategy to achieve an optimal level of performance during a self-paced event. Meanwhile Brick et al. (2015) interviewed elite endurance runners, also reporting the predominant use of an internal associative attentional focus strategy. Finally, the outcome of Ouvrard et al.'s (Ouvrard et al., 2018) study supports Brick et al.'s findings, this time in a sample of French elite cyclists. They studied the relationship between pacing strategies and attentional focus in elite cyclists during a time-trial championship. In the sample of 9 elite cyclists, thoughts related to active self-regulation of the performance (i.e., internal associative focus) or thought related to outward monitoring of the competition (i.e., external associative focus) were correlated with an optimal performance during a $49.3 \mathrm{~km}$ cycling time-trial corresponding to the national championships.

In summary, the scant evidence suggests that skilled athletes could have automatized processes related to effort regulation in their field of expertise and may need fewer resources to perform the same activity, i.e., they might be more efficient at the time of processing stimuli (Ciria et al., 2019). Although there is not much evidence on this, it is plausible that after many years of deliberate practice, expert participants could have already automatized a pacing strategy (in their respective sports) and they would not require to continuously use working memory capacity in order to update the initial plan (Daniels \& Newell, 2003; Englert, 2017; Evans et al., 2016). Moreover, athletes involved in self-paced sports might have 
better inhibitory control (Jacobson \& Matthaeus, 2014a), and hence they would be able to inhibit thoughts unrelated to exercise performance, allowing them to invest more resources or to focus on other relevant aspects of self-paced exercise (i.e., using an associative strategy). However, this issue remains speculative, as studies which aimed to investigate the cognitive/neural factors related to experts and novices only provide a snapshot of the two endpoints of a continuum (Debarnot et al., 2014). Furthermore, although elite and non-elite athletes might differ in key cognitive processing, little is known of the psychological characteristics of elite performance (Spindler et al., 2018).

\section{Perspective}

The present review identifies some gaps in the literature about the role of executive functions in selfpaced exercise. The literature from sports science hypothesizes that the prefrontal cortex plays a key role in exercise, because when exercise intensity increases, brain activity in prefrontal areas increases progressively until the ventilatory threshold; upon reaching this point, prefrontal activity appears to decrease (Robertson \& Marino, 2015, 2016). This reduction has been hypothesized to reflect a reduced role of prefrontal areas in sustaining goal-directed behavior, and in particular in pacing one's activity when performing high intensities exercises (Robertson \& Marino, 2016). However, this is a naive and simplistic vision of brain function, since interpreting any prefrontal cortex involvement is further complicated by the recurrent finding in cognitive neuroscience that prefrontal activity tends to diminish as participants become expert at the performed skills. Therefore, rather than a single brain area or determinant cognitive function having a key role on exercise regulation, an interconnectivity and overlapping exist between different areas and cognitive functions which optimize the process of exercise regulation.

It is fundamental to reaffirm at this point that self-paced aerobic exercise is likely to be a highly complex process, in which a multitude of factors non-related to executive functions can also contribute to the ultimate decision to upregulate or downregulate exercise intensity. Other brain areas via different mechanisms have a role on exercise regulation. For example, brain areas related to interoceptive and motivational process (e.g., the insula and anterior cingulate cortex) are linked to exercise regulation. On the one hand, enhanced interoception (which entails the processing of body signals) in experience athletes might give rise to a better perception of internal cues from peripheral body systems (e.g., muscular and cardiopulmonary; Faull et al., 2018). This implies that interoceptive abilities might facilitate self-paced exercise regulation and to better tolerate fatigue. On the other hand, highly motivated athletes might perceive temptations of stopping exercise as less salient stimulus, which makes goal progress smoother (Taylor et al., 2018). This view implies that motivated athletes will see performance-related discomfort as a less prominent barrier to successful performance, relative to athletes less motivated or with less experience to assess these salient, negative stimuli. 
In relation to the role of the cognitive load during exercise, a key point to consider is the task characteristics. For example, we consider crucial to include (at least) two conditions with different levels of cognitive load to guarantee that any effect on exercise performance is a consequence of the cognitive load and not due to the effect of performing a single task compared to dual-tasking. Moreover, the presence of a single task condition without cognitive activity may result in a change in participants' focus of attention, which in turn it might even be more mentally demanding. Furthermore, the duration and difficulty of the cognitive task and exercise should be considered according to the expertise on the physical test performed by participants. For instance, an athlete might self-regulate correctly for a $5 \mathrm{~km}$ race, but not for a marathon race even if she/he had a high level of fitness. In summary, self-paced exercise is a goal-directed behavior that has been related to both bottom-up and top-down processing. As such, self-paced exercise might be seen as an effortful cognitive task involving body motion that places high demands on several brain areas related to emotional, motivational, interoception and executive processing. Athletes with high level of proficiency or expertise are likely to process these brain signals in a different way than less experienced athletes, but only if it is related to its field of expertise (i.e., being a good at self-pacing in running do not guarantee being good at cycling). Therefore, when we aim to study the mechanisms of self-paced exercise regulation in future studies, we should consider the level of expertise (as well as the other factors mentioned in this review) for determining the effect of these intervention which we have described in this review and for determining which brain areas have a role of exercise regulation.

This research area is still in its infancy and greater efforts are needed to understand the role of executive functions in self-paced exercise. Given that during self-paced exercise there is an apparent interconnectivity between different areas and cognitive functions, we think that the field of sport science and cognitive neuroscience should go hand in hand in order to properly advance in this research area. Key points such as the level of expertise, interoceptive and motivational process, and length of the protocol, should not be neglected when studying the role of executive functions on self-paced exercise. Moreover, we advocate for greater methodological efforts in this field, such as a priori power calculation, data sharing and pre-registration of studies to improve the credibility and reproducibility.

\section{Acknowledgments}

We would like to thank Prof. Daphne Bavelier from the University of Geneva, Switzerland for her constructive and helpful comments during the preparation of this manuscript and the two anonymous Reviewers for their exhaustive and constructive review.

Funding: Daniel Sanabria is awarded with a grant PSI2016-75956-P from Ministerio de Economía, Industria y Competitividad. 
Conflict of interests: none potential conflict

\section{References}

Aron, A. R., Behrens, T. E., Smith, S., Frank, M. J., \& Poldrack, R. A. (2007). Triangulating a cognitive control network using diffusion-weighted magnetic resonance imaging (MRI) and functional MRI. Journal of Neuroscience, 27(14), 3743-3752. https://doi.org/10.1523/JNEUROSCI.0519-07.2007

Audiffren, M., \& André, N. (2015). The strength model of self-control revisited: Linking acute and chronic effects of exercise on executive functions. Journal of Sport and Health Science, 4(1), 30-46. https://doi.org/10.1016/j.jshs.2014.09.002

Baron, B., Moullan, F., Deruelle, F., \& Noakes, T. D. (2011). The role of emotions on pacing strategies and performance in middle and long duration sport events. British Journal of Sports Medicine, 45(6), 511-517. https://doi.org/10.1136/bjsm.2009.059964

Barwood, M. J., Butterworth, J., Goodall, S., House, J. R., Laws, R., Nowicky, A., \& Corbett, J. (2016). The effects of direct current stimulation on exercise performance, pacing and perception in temperate and hot environments. Brain Stimulation, 9(6), 842-849. https://doi.org/10.1016/j.brs.2016.07.006

Bejder, J., Andersen, A. B., Bonne, T. C., Piil, J. F., Hagen, L. C. H., Dehnes, Y., Eibye, K. H., Nybo, L., \& Nordsborg, N. B. (2019). Tramadol does not improve performance or impair motor function in trained cyclists. Medicine and Science in Sports and Exercise, https://doi.org/10.1249/MSS.0000000000002217

Bigliassi, M. (2015). Corollary discharges and fatigue-related symptoms: The role of attentional focus. Frontiers in Psychology, 6, https://doi.org/10.3389/fpsyg.2015.01002

Billaut, F., Davis, J. M., Smith, K. J., Marino, F. E., \& Noakes, T. D. (2010). Cerebral oxygenation decreases but does not impair performance during self-paced, strenuous exercise. Acta Physiologica, 198(4), 477-486. https://doi.org/10.1111/j.1748- 1716.2009.02058.x

Blakely, M. J., Kemp, S., \& Helton, W. S. (2016). Volitional running and tone counting: The impact of cognitive load on running over natural terrain. IIE Transactions on Occupational Ergonomics and Human Factors, 4(2-3), 104-114. https://doi.org/10.1080/21577323.2015.1055864

Brick, N., MacIntyre, T., \& Campbell, M. (2014). Attentional focus in endurance activity: New paradigms and future directions. International Review of Sport and Exercise Psychology, 7(1), 106134. https://doi.org/10.1080/1750984X.2014.885554

Brick, N., MacIntyre, T., \& Campbell, M. (2015). Metacognitive processes in the self-regulation of performance in elite endurance runners. Psychology of Sport and Exercise, 19, 1-9. https://doi.org/10.1016/j.psychsport.2015.02.003

Brownsberger, J., Edwards, A., Crowther, R., \& Cottrell, D. (2013). Impact of mental fatigue on selfpaced exercise. International Journal of Sports Medicine, 34(12), 1029-1036. https://doi.org/10.1055/s0033-1343402

Burke, L. M. (2008). Caffeine and sports performance. Applied Physiology, Nutrition, and Metabolism, 33(6), 1319-1334. https://doi.org/10.1139/H08-130 
Chinnasamy, C., Gibson, A. S. C., \& Micklewright, D. (2013). Effect of spatial and temporal cues on athletic pacing in schoolchildren. Medicine \& Science in Sports \& Exercise, 45(2), 395-402. https://doi.org/10.1249/MSS.0b013e318271edfb

Ciria, L. F., Luque-Casado, A., Sanabria, D., Holgado, D., Ivanov, P. C., \& Perakakis, P. (2019). Oscillatory brain activity during acute exercise: Tonic and transient neural response to an oddball task. Psychophysiology, 56(0), e13326. https://doi.org/10.1111/psyp.13326

Clark, I. E., Goulding, R. P., DiMenna, F. J., Bailey, S. J., Jones, M. I., Fulford, J., McDonagh, S. T. J., Jones, A. M., \& Vanhatalo, A. (2018). Time-trial performance is not impaired in either competitive athletes or untrained individuals following a prolonged cognitive task. European Journal of Applied Physiology, https://doi.org/10.1007/s00421-018-4009-6

Cohen, M. X., Heller, A. S., \& Ranganath, C. (2005). Functional connectivity with anterior cingulate and orbitofrontal cortices during decision-making. Cognitive Brain Research, 23(1), 61-70. https://doi.org/10.1016/j.cogbrainres.2005.01.010

Cona, G., Cavazzana, A., Paoli, A., Marcolin, G., Grainer, A., \& Bisiacchi, P. S. (2015). It's a matter of mind! cognitive functioning predicts the athletic performance in ultra-marathon runners. PLOS One, 10(7), e0132943. https://doi.org/10.1371/journal.pone.0132943

Connolly, C., \& Janelle, C. (2003). Attentional strategies in rowing: Performance, perceived exertion, and gender considerations. Journal of Applied Sport Psychology, 15(3), 195-212. https://doi.org/10.1080/10413200305387

Daniels, G. L., \& Newell, K. M. (2003). Attentional focus influences the walk-run transition in human locomotion. Biological Psychology, 63(2), 163-178. https://doi.org/10.1016/S0301-0511(03)00024-3

Davies, M. J., Clark, B., Welvaert, M., Skorski, S., Garvican-Lewis, L. A., Saunders, P., \& Thompson, K. G. (2016). Effect of environmental and feedback interventions on pacing profiles in cycling: A metaanalysis. Frontiers in Physiology, 7,https://doi.org/10.3389/fphys.2016.00591

Debarnot, U., Sperduti, M., Di Rienzo, F., \& Guillot, A. (2014). Experts bodies, experts minds: How physical and mental training shape the brain. Frontiers in Human Neuroscience, 8, https://doi.org/10.3389/fnhum.2014.00280

de Koning, J. J., Foster, C., Bakkum, A., Kloppenburg, S., Thiel, C., Joseph, T., Cohen, J., \& Porcari, J. P. (2011). Regulation of pacing strategy during athletic competition. PLoS ONE, 6(1), 2-7. https://doi.org/10.1371/journal.pone.0015863

Diamond, A. (2013). Executive functions. Annual Review of Psychology, 64(1), 135-168. https://doi.org/10.1146/annurev-psych-113011-143750

Diamond, A., \& Ling, D. S. (2019). Fundamental questions surrounding efforts to improve executive functions (including working memory). In M. Bunting, J. Novick, M. Dougherty, \& R. W. Engle (Eds.), An integrative approach to cognitive and working memory training: Perspectives from psychology, neuroscience, and human development (pp. 143-431). Oxford University Press.

Dietrich, A., \& Audiffren, M. (2011). The reticular-activating hypofrontality (RAH) model of acute exercise. Neuroscience \& Biobehavioral Reviews, 35(6), 1305-1325. https://doi.org/10.1016/j.neubiorev.2011.02.001 
Edwards, A. M., \& Polman, R. C. J. (2013). Pacing and awareness: Brain regulation of physical activity. Sports Medicine, 43(11), 1057-1064. https://doi.org/10.1007/s40279-013-0091-4

Enders, H., Cortese, F., Maurer, C., Baltich, J., Protzner, A. B., \& Nigg, B. M. (2016). Changes in cortical activity measured with EEG during a high intensity cycling exercise. Journal of Neurophysiology, 115(1), 379-388. Jn.00497.2015, https://doi.org/10.1152/jn.00497.2015

Englert, C. (2017). Ego depletion in sports: Highlighting the importance of self-control strength for high-level sport performance. Current Opinion in Psychology, 16, 1-5. https://doi.org/10.1016/j.copsyc.2017.02.028

Enriquez-Geppert, S., Huster, R. J., \& Herrmann, C. S. (2013). Boosting brain functions: Improving executive functions with behavioral training, neurostimulation, and neurofeedback. International Journal of Psychophysiology, 88(1), 1-16. https://doi.org/10.1016/j.ijpsycho.2013.02.001

Epling, S. L., Blakely, M. J., Russell, P. N., \& Helton, W. S. (2016). Free recall and outdoor running: Cognitive and physical demand interference. Experimental Brain Research, 234(10), 2979-2987. https://doi.org/10.1007/s00221-016-4700-y

Erickson, K. I., Colcombe, S. J., Wadhwa, R., Bherer, L., Peterson, M. S., Scalf, P. E., Kim, J. S., Alvarado, M., \& Kramer, A. F. (2006). Training-induced functional activation changes in dual-task processing: An FMRI study. Cerebral Cortex, 17(1), 192-204. https://doi.org/10.1093/cercor/bhj137

Evans, D. R., Boggero, I. A., \& Segerstrom, S. C. (2016). The nature of self-regulatory fatigue and "ego depletion": Lessons from physical fatigue. Personality and Social Psychology Review, 20(4), 291-310. https://doi.org/10.1177/1088868315597841

Faull, O. K., Cox, P. J., \& Pattinson, K. T. S. (2018). Cortical processing of breathing perceptions in the athletic brain. NeuroImage, 179, 92-101. https://doi.org/10.1016/j.neuroimage.2018.06.021

Filipas, L., Mottola, F., Tagliabue, G., \& La Torre, A. (2018). The effect of mentally demanding cognitive tasks on rowing performance in young athletes. Psychology of Sport and Exercise, 39, $52-$ 62. https://doi.org/10.1016/j.psychsport.2018.08.002

Floyer-Lea, A., \& Matthews, P. M. (2005). Distinguishable brain activation networks for short- and long-term motor skill learning. Journal of Neurophysiology, 94(1), 512-518. https://doi.org/10.1152/jn.00717.2004

Fontes, E. B., Bortolotti, H., da Costa, K. G., de Campos, B. M., Castanho, G. K., Hohl, R., Noakes, T., $\&$ Min, L. L. (2020). Modulation of cortical and subcortical brain areas at low and high exercise intensities. British Journal of Sports Medicine, 54(2), 110-115. https://doi.org/10.1136/bjsports-2018100295

Foster, C., Hendrickson, K. J., Peyer, K., Reiner, B., de Koning, J. J., Lucia, A., Battista, R. A., Hettinga, F. J., Porcari, J. P., \& Wright, G. (2009). Pattern of developing the performance template. British Journal of Sports Medicine, 43(10), 765-769. https://doi.org/10.1136/bjsm.2008.054841

Franco-Alvarenga, P. E., Brietzke, C., Canestri, R., Goethel, M. F., Hettinga, F., Santos, T. M., \& Pires, F. O. (2019). Caffeine improved cycling trial performance in mentally fatigued cyclists, regardless of alterations in prefrontal cortex activation. Physiology \& Behavior, 204, 41-48. https://doi.org/10.1016/j.physbeh.2019.02.009 
Friedman, N. P., \& Miyake, A. (2017). Unity and diversity of executive functions: Individual differences as a window on cognitive structure. Cortex, 86, 186-204. https://doi.org/10.1016/j.cortex.2016.04.023

Furley, P., \& Memmert, D. (2011). Studying cognitive adaptations in the field of sport: Broad or narrow transfer? A comment on Allen, Fioratou, and McGeorge (2011). Perceptual and Motor Skills, 113(2), 481-488. https://doi.org/10.2466/05.23.PMS.113.5.481- 488

Ganio, M., Klau, J., Casa, D., Armstrong, L., \& Maresh, C. (2009). Effect of caffeine on sport-specific endurance performance: A systematic review. Journal of Strength and Conditioning Research, 23(1), 315-324. https://doi.org/10.1519/JSC.0b013e31818b979a

Giles, G. E., Cantelon, J. A., Eddy, M. D., Brunyé, T. T., Urry, H. L., Taylor, H. A., Mahoney, C. R., $\&$ Kanarek, R. B. (2018). Cognitive reappraisal reduces perceived exertion during endurance exercise. Motivation and Emotion, 42(4), 482-496. https://doi.org/10.1007/s11031-018-9697-z

Grgic, J., Grgic, I., Pickering, C., Schoenfeld, B. J., Bishop, D. J., \& Pedisic, Z. (2019). Wake up and smell the coffee: Caffeine supplementation and exercise performance-an umbrella review of 21 published meta-analyses. British Journal of Sports Medicine, https://doi.org/10.1136/bjsports-2018100278

Halperin, I., \& Emanuel, A. (2019). Rating of perceived effort: Methodological concerns and future directions. Sports Medicine, https://doi.org/10.1007/s40279-019-01229-z

Harris, D. J., Wilson, M. R., \& Vine, S. J. (2018). A systematic review of commercial cognitive training devices: Implications for use in sport. Frontiers in Psychology, 9, https://doi.org/10.3389/fpsyg.2018.00709

Hatzigeorgiadis, A., Zourbanos, N., Galanis, E., \& Theodorakis, Y. (2011). Self-talk and sports performance: A meta-analysis. Perspectives on Psychological Science, 6(4), 348-356. https://doi.org/10.1177/1745691611413136

Hilty, L., Langer, N., Pascual-Marqui, R., Boutellier, U., \& Lutz, K. (2011). Fatigue-induced increase in intracortical communication between mid/anterior insular and motor cortex during cycling exercise. The European Journal of Neuroscience, 34(12), 2035-2042. https://doi.org/10.1111/j.14609568.2011.07909.x

Holgado, D., Hopker, J., Sanabria, D., \& Zabala, M. (2018). Analgesics and sport performance: Beyond the pain-modulating effects. PM\&R, 10(1), 72-82. https://doi.org/10.1016/j.pmrj.2017.07.068

Holgado, D., Vadillo, M. A., \& Sanabria, D. (2018). The effects of transcranial direct current stimulation on objective and subjective indexes of exercise performance: A systematic review and metaanalysis. Brain Stimulation: Basic, Translational, and Clinical Research in Neuromodulation, 0(0). https://doi.org/10.1016/j.brs.2018.12.002

Holgado, D., Zabala, M., \& Sanabria, D. (2019). No evidence of the effect of cognitive load on self$\begin{array}{lllll}\text { paced cycling } & \text { Performance. } & \text { PLOS } 217825 .\end{array}$ https://doi.org/10.1371/journal.pone.0217825

Holgado, D., Zandonai, T., Ciria, L., Zabala, M., Hopker, J., \& Sanabria, D. (2019). Transcranial direct current stimulation (tDCS) over the left prefrontal cortex does not affect time-trial self-paced cycling 
performance: Evidence from oscillatory brain activity and power output. PLOS One, 14(2), e0210873. https://doi.org/10.1371/journal.pone.0210873

Holgado, D., Zandonai, T., Zabala, M., Hopker, J., Perakakis, P., Luque-Casado, A., Ciria, L., GuerraHernandez, E., \& Sanabria, D. (2018). Tramadol effects on physical performance and sustained attention during a 20-min indoor cycling time-trial: A randomised controlled trial. Journal of Science and Medicine in Sport, 21(7), 654-660. https://doi.org/10.1016/j.jsams.2017.10.032

Hutchinson, J. C., \& Tenenbaum, G. (2007). Attention focus during physical effort: The mediating role of task intensity. Psychology of Sport and Exercise, 8(2), 233-245. https://doi.org/10.1016/j.psychsport.2006.03.006

Hyland-Monks, R., Cronin, L., McNaughton, L., \& Marchant, D. (2018). Chapter 19 - The role of executive function in the self regulation of endurance performance: A critical review. In S. Marcora \& M. Sarkar (Eds.), Progress in brain research (Vol. 240, pp. 353-370). Elsevier. https://doi.org/10.1016/bs.pbr.2018.09.011

Jacobson, J., \& Matthaeus, L. (2014b). Athletics and executive functioning: How athletic participation and sport type correlate with cognitive performance. Psychology of Sport and Exercise, 15(5), 521527. https://doi.org/10.1016/j.psychsport.2014.05.005

Johnson, B. D., Joseph, T., Wright, G., Battista, R. A., Dodge, C., Balweg, A., de Koning, J. J., \& Foster, C. (2009). Rapidity of responding to a hypoxic challenge during exercise. European Journal of Applied Physiology, 106(4), 493-499. https://doi.org/10.1007/s00421-009-1036-3

Krenn, B., Finkenzeller, T., Würth, S., \& Amesberger, G. (2018). Sport type determines differences in executive functions in elite athletes. Psychology of Sport and Exercise, 38, 72-79. https://doi.org/10.1016/j.psychsport.2018.06.002

Lambourne, K., \& Tomporowski, P. (2010). The effect of exercise-induced arousal on cognitive task performance: A meta regression analysis. Brain Research, 1341, 12-24. https://doi.org/10.1016/j.brainres.2010.03.091

León-Domínguez, U., \& León-Carrión, J. (2019). Prefrontal neural dynamics in consciousness. Neuropsychologia, 131, 25-41. https://doi.org/10.1016/j.neuropsychologia.2019.05.018

Ludyga, S., Gerber, M., Brand, S., Holsboer-Trachsler, E., \& Pühse, U. (2016). Acute effects of moderate aerobic exercise on specific aspects of executive function in different age and fitness groups: A meta-analysis. Psychophysiology, 53(11), 1611-1626. https://doi.org/10.1111/psyp.12736

Ludyga, S., Gronwald, T., \& Hottenrott, K. (2015). The athlete's brain: Cross-sectional evidence for neural efficiency during cycling exercise. Neural Plasticity, 2016, https://doi.org/10.1155/2016/4583674

Lundberg, T. R., \& Howatson, G. (2018). Analgesic and anti-inflammatory drugs in sports: Implications for exercise performance and training adaptations. Scandinavian Journal of Medicine \& Science in Sports, 28(11), 2252-2262. https://doi.org/10.1111/sms.13275

Lutz, K. (2018). Chapter 18-Functional brain anatomy of exercise regulation. In S. Marcora \& M. Sarkar (Eds.), Progress in brain research (Vol. 240, pp. 341-352). Elsevier. https://doi.org/10.1016/bs.pbr.2018.07.006 
Machado, D. G. d. S., Unal, G., Andrade, S. M., Moreira, A., Altimari, L. R., Brunoni, A. R., Perrey, S., Mauger, A. R., Bikson, M., \& Okano, A. H. (2018). Effect of transcranial direct current stimulation on exercise performance: A systematic review and meta-analysis. Brain Stimulation: Basic, Translational, and Clinical Research in Neuromodulation, $0(0)$, https://doi.org/10.1016/j.brs.2018.12.227

MacMahon, C., Schücker, L., Hagemann, N., \& Strauss, B. (2014). Cognitive fatigue effects on physical performance during running. Journal of Sport \& Exercise Psychology, 36(4), 375-381. https://doi.org/10.1123/jsep.2013-0249

Malcolm, B. R., Foxe, J. J., Butler, J. S., Molholm, S., \& De Sanctis, P. (2018). Cognitive load reduces the effects of optic flow on gait and electrocortical dynamics during treadmill walking. Journal of Neurophysiology, https://doi.org/10.1152/jn.00079.2018

Marcora, S., Staiano, W., \& Manning, V. (2009). Mental fatigue impairs physical performance in humans. Journal of Applied Physiology, 106(3), 857-864. https://doi.org/10.1152/japplphysiol.91324.2008

Martin, K., Meeusen, R., Thompson, K. G., Keegan, R., \& Rattray, B. (2018). Mental fatigue impairs endurance performance: A physiological explanation. Sports Medicine, https://doi.org/10.1007/s40279018-0946-9

Martin, K., Staiano, W., Menaspà, P., Hennessey, T., Marcora, S., Keegan, R., Thompson, K. G., Martin, D., Halson, S., \& Rattray, B. (2016). Superior inhibitory control and resistance to mental fatigue in professional road cyclists. Plos One, 11(7), e0159907. https://doi.org/10.1371/journal.pone.0159907

Mauger, A. R., Jones, A. M., \& Williams, C. A. (2010). Influence of Acetaminophen on performance during time trial cycling. Journal of Applied Physiology, 108(1), 98-104. https://doi.org/10.1152/japplphysiol.00761.2009

McCormick, A., Meijen, C., \& Marcora, S. (2015). Psychological determinants of whole-body endurance performance. Sports Medicine, 1-19. https://doi.org/10.1007/s40279-015-0319-6

McMorris, T., Barwood, M., \& Corbett, J. (2018). Central fatigue theory and endurance exercise: Toward an interoceptive model. Neuroscience and Biobehavioral Reviews, 93, 93-107. https://doi.org/10.1016/j.neubiorev.2018.03.024

Meester, D., Al-Yahya, E., Dawes, H., Martin-Fagg, P., \& Piñon, C. (2014). Associations between prefrontal cortex activation and H-reflex modulation during dual task gait. Frontiers in Human Neuroscience, 8, https://doi.org/10.3389/fnhum.2014.00078

Morgan, W. P., \& Pollock, M. L. (1977). Psychologic characterization of the elite distance runner. Annals of the New York Academy of Sciences, 301(1), 382-403. https://doi.org/10.1111/j.17496632.1977.tb38215.x

Neubauer, A. C., \& Fink, A. (2009). Intelligence and neural efficiency. Neuroscience \& Biobehavioral Reviews, 33(7), 1004-1023. https://doi.org/10.1016/j.neubiorev.2009.04.001

Noakes, T. D. (2011). Time to move beyond a brainless exercise physiology: The evidence for complex regulation of human exercise performance. Applied Physiology, Nutrition, and Metabolism, 36(1), 2335. https://doi.org/10.1139/H10-082 
Ouvrard, T., Groslambert, A., \& Grappe, F. (2018). The influence of pleasure and attentional focus on performance and pacing strategies in elite individual time trials. International Journal of Sports Physiology and Performance, 1-22. https://doi.org/10.1123/ijspp.2017-0773

Pageaux, B. (2014). The psychobiological model of endurance performance: An effort-based decisionmaking theory to explain self-paced endurance performance. Sports Medicine, 44, 1319-1320. https://doi.org/10.1007/s40279-014-0198-2

Pageaux, B. (2016). Perception of effort in exercise science: Definition, measurement and perspectives. European Journal of Sport Science, 16(8), 885-894. https://doi.org/10.1080/17461391.2016.1188992

Pageaux, B., Lepers, R., Dietz, K. C., \& Marcora, S. M. (2014). Response inhibition impairs subsequent self-paced endurance performance. European Journal of Applied Physiology, 114(5), 1095-1105. https://doi.org/10.1007/s00421-014-2838-5

Penna, E. M., Filho, E., Wanner, S. P., Campos, B. T., Quinan, G. R., Mendes, T. T., Smith, M. R., \& Prado, L. S. (2018). Mental fatigue impairs physical performance in young swimmers. Pediatric Exercise Science, 30(2), 208-215. https://doi.org/10.1123/pes.2017-0128

Pires, F. O., Silva-Júnior, F. L., Brietzke, C., Franco-Alvarenga, P. E., Pinheiro, F. A., de França, N. M., Teixeira, S., \& Meireles Santos, T. (2018). Mental fatigue alters cortical activation and psychological responses, impairing performance in a distance based cycling trial. Frontiers in Physiology, 9), https://doi.org/10.3389/fphys.2018.00227

Pollatos, O., Gramann, K., \& Schandry, R. (2007). Neural systems connecting interoceptive awareness and feelings. Human Brain Mapping, 28(1), 9-18. https://doi.org/10.1002/hbm.20258

Reardon, S. (2016). 'Brain doping' may improve athletes' performance. Nature, 531(7594), 283-284. https://doi.org/10.1038/nature.2016.19534

Renfree, A., Martin, L., Micklewright, D., \& St Clair Gibson, A. (2014). Application of decisionmaking theory to the regulation of muscular work rate during self-paced competitive endurance activity. Sports Medicine, 44(2), 147-158. https://doi.org/10.1007/s40279-013-0107-0

Robertson, C. V., \& Marino, F. E. (2015). Prefrontal and motor cortex EEG responses and their relationship to ventilatory thresholds during exhaustive incremental exercise. European Journal of Applied Physiology, 115(9), 1939-1948. https://doi.org/10.1007/s00421-015-3177-x

Robertson, C. V., \& Marino, F. E. (2016). A role for the prefrontal cortex in exercise tolerance and termination. Journal of Applied Physiology, 120(4), 464-466. https://doi.org/10.1152/japplphysiol.00363.2015

Robinson, D. T., Cloak, R., Lahart, I. M., \& Lane, A. M. (2018). Chapter 8 - Do I focus on the process of cycling or try to put my mind elsewhere? A comparison of concentration strategies for use in pacing by novice riders. In S. Marcora \& M. Sarkar (Eds.), Progress in brain research (Vol. 240, pp. 127-140). Elsevier. https://doi.org/10.1016/bs.pbr.2018.09.005

Roelands, B., De Koning, J., Foster, C., Hettinga, F., \& Meeusen, R. (2013). Neurophysiological determinants of theoretical concepts and mechanisms involved in pacing. Sports Medicine, 43(5), 301311. https://doi.org/10.1007/s40279-013-0030-4 
Schaefer, S. (2014). The ecological approach to cognitive-motor dual-tasking: Findings on the effects of expertise and age. Frontiers in Psychology, 5, https://doi.org/10.3389/fpsyg.2014.01167

Schaefer, S., Jagenow, D., Verrel, J., \& Lindenberger, U. (2015). The influence of cognitive load and walking speed on gait regularity in children and young adults. Gait \& Posture, 41(1), 258-262. https://doi.org/10.1016/j.gaitpost.2014.10.013

Schiphof-Godart, L., Roelands, B., \& Hettinga, F. J. (2018). Drive in sports: How mental fatigue affects endurance performance. Frontiers in Psychology, 9(Aug), https://doi.org/10.3389/fpsyg.2018.01383

Schmidt, R., \& Lee, T. (2014). Motor learning and performance 5th edition with web study guide (5th ed.). Human Kinetics.

Silva-Cavalcante, M. D., Couto, P. G., Azevedo, R. d. A., Silva, R. G., Coelho, D. B., Lima-Silva, A. E., \& Bertuzzi, R. (2018). Mental fatigue does not alter performance or neuromuscular fatigue development during self-paced exercise in recreationally trained cyclists. European Journal of Applied Physiology, 118(11), 2477-2487. https://doi.org/10.1007/s00421-018-3974-0

Silva, J. M., \& Appelbaum, M. I. (1989). Association-dissociation patterns of United States Olympic marathon trial contestants. Cognitive Therapy and Research, 13(2), 185-192. https://doi.org/10.1007/BF01173272

Simpson, M. (2017). The use of transcranial direct current stimulation (tDCS) to explore how risk characteristics influence athletic pacing [Doctoral dissertation, University of Essex]. http://repository.essex.ac.uk/id/eprint/18852

Smits, B. L. M., Pepping, G. J., \& Hettinga, F. J. (2014). Pacing and decision making in sport and exercise: The roles of perception and action in the regulation of exercise intensity. Sports Medicine, 44(6), 763-775. https://doi.org/10.1007/s40279-014-0163-0

Spindler, D. J., Allen, M. S., Vella, S. A., \& Swann, C. (2018). The psychology of elite cycling: A systematic review. Journal of Sports Sciences, 36(17), 1943-1954. https://doi.org/10.1080/02640414.2018.1426978

Staiano, W., Bosio, A., Piazza, G., Romagnoli, M., \& Invernizzi, P. L. (2018). Kayaking performance is altered in mentally fatigued young elite athletes. The Journal of Sports Medicine and Physical Fitness, https://doi.org/10.23736/S0022-4707.18.09051-5

St Clair Gibson, A., Lambert, E. V., Rauch, L. H. G., Tucker, R., Baden, D. A., Foster, C., \& Noakes, T. D. (2006). The role of information processing between the brain and peripheral physiological systems in pacing and perception of effort. Sports Medicine, 36(8), 705-722. https://doi.org/10.2165/00007256200636080-00006

Stevinson, C. D., \& Biddle, S. J. (1998). Cognitive orientations in marathon running and "hitting the wall”. British Journal of Sports Medicine, 32(3), 229-234. https://doi.org/10.1136/bjsm.32.3.229

Suzuki, M., Miyai, I., Ono, T., Oda, I., Konishi, I., Kochiyama, T., \& Kubota, K. (2004). Prefrontal and premotor cortices are involved in adapting walking and running speed on the treadmill: An optical imaging study. NeuroImage, 23(3), 1020-1026. https://doi.org/10.1016/j.neuroimage.2004.07.002 
Taylor, I. M., Boat, R., \& Murphy, S. L. (2018). Integrating theories of self-control and motivation to advance endurance performance. International Review of Sport and Exercise Psychology, 0(0), 1-20. https://doi.org/10.1080/1750984X.2018.1480050

Valenzuela, P. L., Amo, C., Sánchez-Martínez, G., Torrontegi, E., Vázquez-Carrión, J., Montalvo, Z., Lucia, A., \& de la Villa, P. (2018). Transcranial direct current stimulation enhances mood but not performance in elite athletes. International Journal of Sports Physiology and Performance, 1-20. https://doi.org/10.1123/ijspp.2018-0473

Van Cutsem, J., De Pauw, K., Marcora, S., Meeusen, R., \& Roelands, B. (2018). A caffeinemaltodextrin mouth rinse counters mental fatigue. Psychopharmacology, 235(4), 947-958. Scopus. https://doi.org/10.1007/s00213-017-4809-0

Van Cutsem, J., Marcora, S., De Pauw, K., Bailey, S., Meeusen, R., \& Roelands, B. (2017). The effects of mental fatigue on physical performance: A systematic review. Sports Medicine, 47(8), 1569-1588. Scopus. https://doi.org/10.1007/s40279-016-0672-0

Venhorst, A., Micklewright, D., \& Noakes, T. D. (2018). Towards a three-dimensional framework of centrally regulated and goaldirected exercise behaviour: A narrative review. British Journal of Sports Medicine, 52(15), 957-966. https://doi.org/10.1136/bjsports-2016-096907

Verhoeven, K., Van Damme, S., Eccleston, C., Van Ryckeghem, D. M. L., Legrain, V., \& Crombez, G. (2011). Distraction from pain and executive functioning: An experimental investigation of the role of inhibition, task switching and working memory. European Journal of Pain, 15(8), 866-873. https://doi.org/10.1016/j.ejpain.2011.01.009

Vickers, J. N., \& Williams, A. M. (2017). The role of mental processes in elite sports performance. Oxford research encyclopedia psychology. https://doi.org/10.1093/acrefore/9780190236557.013.161

Walton, C. C., Keegan, R. J., Martin, M., \& Hallock, H. (2018). The potential role for cognitive training in sport: More research needed. Frontiers in Psychology, 9, https://doi.org/10.3389/fpsyg.2018.01121

Williams, E. L., Jones, H. S., Sparks, S. A., Marchant, D. C., Midgley, A. W., Bridge, C. A., \& McNaughton, L. R. (2016). Deceptive manipulation of competitive starting strategies influences subsequent pacing, physiological status, and perceptual responses during cycling time trials. Frontiers in Physiology, 7, https://doi.org/10.3389/fphys.2016.00536

Williams, E. L., Jones, H. S., Sparks, S. A., Marchant, D. C., Midgley, A. W., \& Naughton, L. R. M. (2015). Competitor presence reduces internal attentional focus and improves $16.1 \mathrm{~km}$ cycling time trial performance. Journal of Science and Medicine in Sport, 18(4), 486-491. https://doi.org/10.1016/j.jsams.2014.07.003

Williamson, J. W., Nobrega, A. C. L., McColl, R., Mathews, D., Winchester, P., Friberg, L., \& Mitchell, J. H. (1997). Activation of the insular cortex during dynamic exercise in humans. The Journal of Physiology, 503(2), 277-283. https://doi.org/10.1111/j.1469-7793.1997.277bh.x

Wolff, W., Bieleke, M., Hirsch, A., Wienbruch, C., Gollwitzer, P. M., \& Schüler, J. (2018). Increase in prefrontal cortex oxygenation during static muscular endurance performance is modulated by selfregulation strategies. Scientific Reports, 8(1), 1-10. https://doi.org/10.1038/s41598-018-34009-2 
